\title{
Swimmers Are At Risk For Stress Fractures? A Systematic Review
}

\author{
Angelo V. Vasiliadis*1, Vasileios Lampridis ${ }^{2}$, Dimitrios Georgiannos ${ }^{3}$, Ilias Bisbinas ${ }^{3}$ \\ ${ }^{1}$ Department of Orthopaedic and Trauma Surgery, General Hospital of Katerini, 6km Katerinis-Arona, Katerini 60100, Greece \\ ${ }^{2}$ Frimley Park Hospital, NHS Surrey, United Kingdom \\ ${ }^{3}$ Department of Orthopaedic and Trauma Surgery, 424 Military General Hospital, Thessaloniki, Greece
}

Corresponding Author: Angelo V. Vasiliadis, E-mail: vasiliadis.av@gmail.com

\section{ARTICLE INFO}

\section{Article history}

Received: May 15, 2018

Accepted: June 30, 2018

Published: July 31, 2018

Volume: 6 Issue: 3

Conflicts of interest: None

Funding: None

\begin{abstract}
Background: Stress fractures occur most commonly in the weight-bearing bones of the lower extremities. Swimming, a non-weight-bearing activity, is a potential activity form which associated with stress fractures? Objective: This systematic review aims to provide an answer in the above question and also to identify the reported cases of stress fractures among swimmers. Method: A systematic and comprehensive search was conducted using PubMed and Research Gate databases before January 2017. The search process was completed using the keywords: "stress fracture", "stress injury", "fatigue fracture", "swimming" and "swimmers". Results: There have been only 10 studies describing stress fractures in swimmers. This rare type of injury is commonly diagnosed in the ribs of young competitive swimmers, irrespective of their preferred swimming stroke. The etiology is multifactorial and includes a combination of intrinsic and/or extrinsic factors. Conclusion: Although any sport activity can potential cause a stress fracture, competitive swimming seems to be relatively safe in this respect. Rib stress fractures appear as the most common stress fracture in competitive swimmers that clinicians should consider. A prompt diagnosis can shorten the time required for healing and decrease the risk of complication.
\end{abstract}

Key words: Stress Fracture, Swimming, Biomechanics, Diagnosis, Treatment

\section{INTRODUCTION}

Historically, stress fractures were first described by Aristotle in $200 \mathrm{BC}$ and were initially documented in the metatarsals of Prussian soldiers by Breithaupt in 1855 (Breithaupt, 1855). The earliest known diagnosis of a stress fracture was given for the femoral shaft in an athlete by Pirker in 1934 (Pirker, 1934). In athletes, the first clinical and radiographic description was provided in a swimmer with a tibia fatigue fracture (Samuel, 1955).

A stress fracture occurs in the bones of a healthy individual, and is associated with repetitive force and overuse of the extremity (Asano, Duarte Jr, \& Silva, 2014). However, a stress fracture can also arise from the normal use of an osteoporotic bone (Tins et al., 2015). Stress fractures most commonly occur in the weight-bearing bones of the lower extremities in athletes who participate in sports such as track and field, basketball, soccer, and dance as the result of repeated running or jumping movements. In contrast, sports involving low-impact repetitive loading, such as: diving, rowing, hockey, tennis, volleyball, golf, fencing, and softball are associated with very low reported incidences of stress fractures (Sanderlin \& Raspa, 2003). The anatomic location of stress fractures is related to the type of sport and the anatomic region which has to absorb the load. As result, runners may develop a stress fracture of the tibia, metatarsals and fibula. Basketball athletes present a predominance of navicular bone and metatarsal stress fractures, soccer players experience a predominance of metatarsal stress fractures, while classical ballet dancers, tennis and volleyball players show a predominance of navicular and sesamoid bone stress fractures (Sanderlin \& Raspa, 2003; Asano, Duarte Jr, \& Silva, 2014).

In recent years, the popularity of swimming, as well as open water swimming has been a fast growing activity during childhood and adolescence. Its popularity based on the fact that it is an excellent way to work your entire body and cardiovascular system, without putting stress in the joints and bones (Lazar et al. 2013). There is general consensus that swimming is an excellent exercise for the cardiovascular system (Lazar et al., 2013). Swimming is also a safe exercise to build muscular strength and prevent bone fractures (Sanderlin \& Raspa, 2003). However, swimming has no positive effect on bone mineral density and is not the best exercise for improving bone strength because it is not a weight-bearing activity (Lee \& Kim, 2015). At present, little is known about the relationship between swimming and the 
development of a stress fracture. As a result, there are two relevant questions that remain to be answered:

- Swimming, a non-weight-bearing activity, is a potential activity form which associated with stress fractures?

- Which are the particular bones that those fractures occur in competitive swimmers?

In addition, others objectives of this systematic review study is to provide a panorama of the literature regarding stress fractures in competitive swimmers, consider the anatomic regions involved in common stress fractures, and provide an updated overview of etiology, diagnosis and treatment.

\section{MATERIAL AND METHODS}

This systematic review was conducted using PubMed and ResearchGate during a date range of database inception until 1 January 2017. The search used combinations of the terms "stress fracture", "stress injury", "fatigue fracture", "swimming" and "swimmers". From this search, a list of publications was established that described or referenced in stress fractures among swimmers. To qualify for inclusion studies had to: (1) include original data; (2) include stress fractures in swimmers; (3) be available in full text; and (4) written in the English language. Studies were excluded if they did not meet the above criteria, or if they were not specific to the swimming athletes. Finally, a total of ten studies met the inclusion criteria and were included in the review. Hard copies of all included publications were distributed to each participating author for review. Figure 1 demonstrates the search and selection process for the present systematic review. The primary search of the literature identified 29 published articles. After removing 4 duplicates, 25 articles remained. Articles were then screened based on titles, abstracts and relevance to the search topic; this process removed 19 articles. Four additional articles were also added from hand-searching reference list from the remaining articles. Finally, 10 articles met inclusion for the ongoing analysis.

\section{RESULTS}

Ten articles were included in the present systematic review that examined stress fractures occurred among swimmers. Articles included in the review were published between 1955 and 2016

\section{Epidemiology}

\section{Population}

Competitive swimmers can potentially suffer from stress fractures, especially in ribs (Table 1) (Chaudhury, Hobart, \& Rodeo, 2012; Heincelman et al., 2014; Low, Kern, \& Atanda, 2016; Taimela, Kujala, \& Orava, 1995;).

\section{Anatomical region}

Stress fractures are closely associated with the daily overuse and repetitive activity that athletes undertake. Regarding athlete swimmers, there is a predominance of stress fractures in the rib cage and particularly in the ribs, rather than in the lower limbs and foot (Figure 2) (Chaudhury, Hobart, \& Rodeo, 2012; Heincelman et al., 2014; Low, Kern, \& Atanda, 2016; Taimela, Kujala, \& Orava, 1995). However, single cases of stress fracture of the tibia (Samuel, 1955), femoral neck (Haddad et al., 1997), pubic ramus (Kim, Park, \& Gartland, 1987), meta tarsal (Van Caspel \& Heere, 1983), fabella (Woo, 1988), and humerus (Sterling,
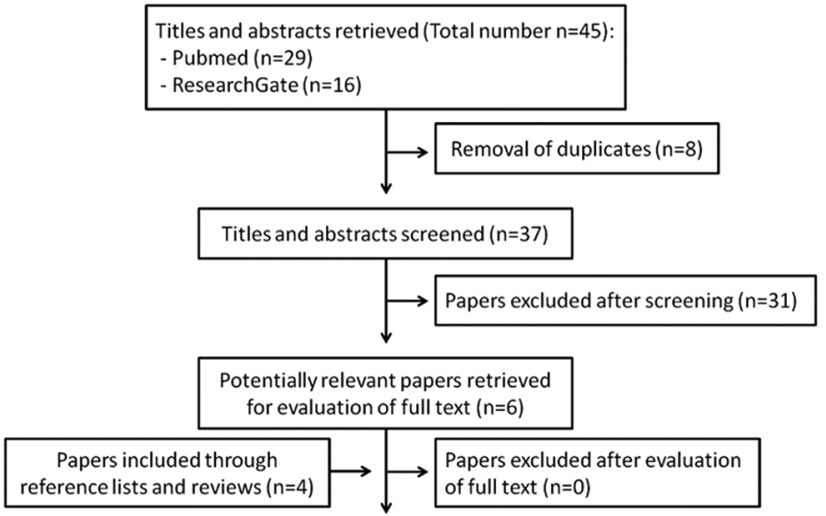

Papers included after review of full

text and for ongoing analysis $(n=10)$

Figure 1. Flow diagram of retrieved, screened and included studies

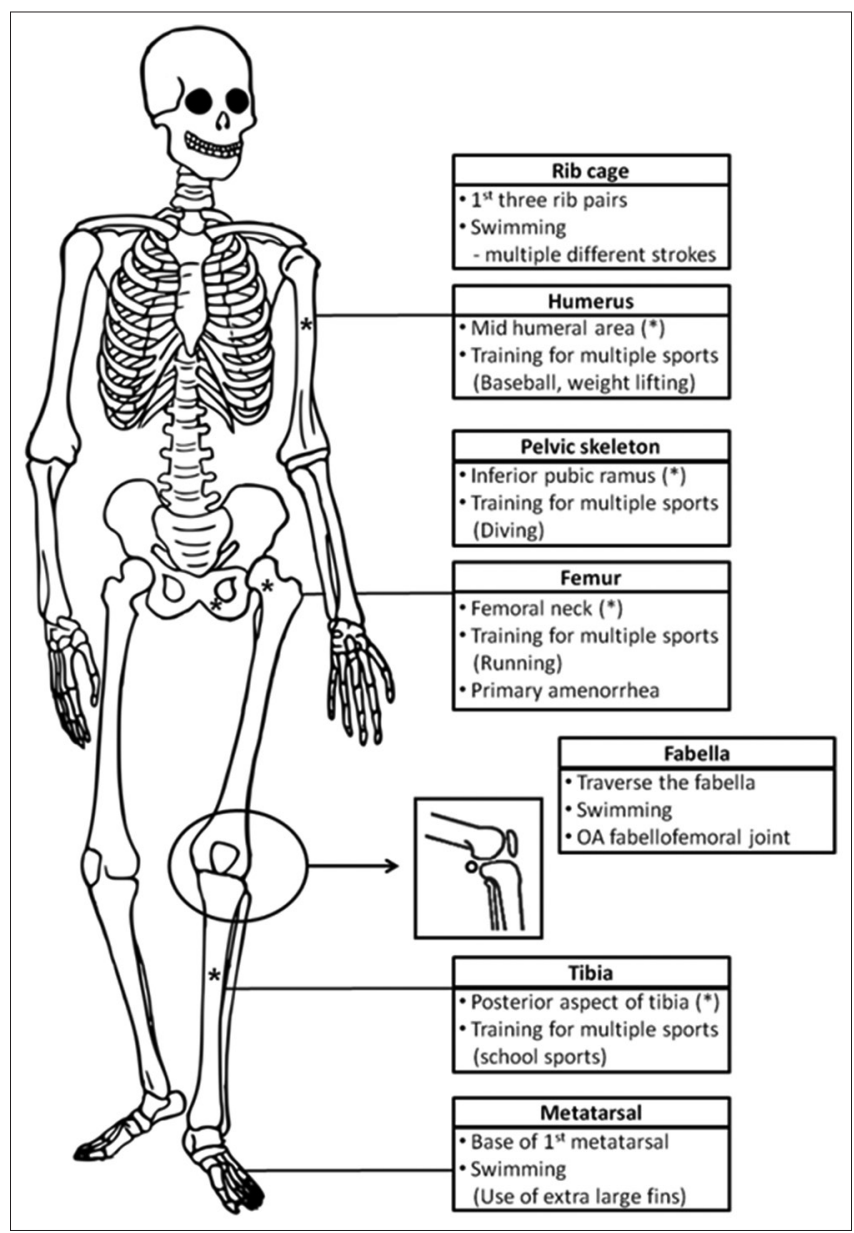

Figure 2. Anatomical locations of stress fractures in swimmers depending the existed cofactors 
Calvo, \& Holden, 1991) have previously been reported in the literature (Table 1).

\section{Type of swimming stroke}

There is no difference in the frequency of stress fractures among the four different strokes used in swimming freestyle, backstroke, butterfly and breaststroke; in regards with rib stress fractures (Table 1).

\section{Gender and age}

Among case studies of athletes, no gender difference appears in the incidence of stress fractures (Table 1). Reported stress fractures occur between the ages of 14 and 53 years, while most frequently seen the young people and young adults (14 to 21 years old), without gender difference regarding the age of occurrence (Samuel, 1955; Chaudhury, Hobart, \& Rodeo, 2012; Haddad et al., 1997; Heincelman et al., 2014; Kim, Park, \& Gartland, 1987; Low, Kern, \& Atanda, 2016; Taimela, Kujala, \& Orava, 1995; Van Caspel \& Heere, 1983; Woo, 1988; Sterling, Calvo, \& Holden, 1991).

\section{Etiology of Injury - Biomechanics of Swimming}

Stress fractures are common injuries among runners at all competitive levels; however, this type of injury seems to be uncommon in competitive swimmers. In swimmers, stress fractures most commonly involve the ribs and a potential role of the biomechanics of swimming may be suspected. The etiology of these fractures is not fully understood; however, multiple factors have been blamed. Typically, these factors are classified as intrinsic (gender, bone mineral density and hormonal factors) or extrinsic types (training load, improper technique and sleep deprivation) (Mayer et al., 2014). Bone is a dynamic tissue with a continuous process of adaptation between the accumulation of microdamage and the remodeling processes. If a factor disrupts this dynamic balance, a stress fracture occurs because of the stresses placed on the bone (DiFiori et al., 2014).

According to the literature, the specific biomechanics of swimming in combination with the imbalance of intrinsic and extrinsic factors may be crucial in order to develop a stress fracture (Sanderlin \& Raspa, 2003). There are four types of strokes, divided into two style groups: i) symmetric style (breaststroke and butterfly stroke); and ii) asymmetric style (freestyle stroke and backstroke) (Figure 3) (Secchi et al., 2010). Swimming is an entire-body exercise and, irrespective of the style, consists of repeating a specific body motion to push against the water and generate thrust. Recently, electromyography and biomechanic analysis of both style categories and all four competitive swimming strokes show that latissimus dorsi and pectoralis major are the predominately pull-through phase muscles (Martens, Figueiredo, \& Daly, 2015). These muscles are the main muscles surrounding the rib cage; consequently it is unsurprising that the majority of the reported stress fractures occur in the ribs.

Table 1. Literature of stress fractures during swimming

\begin{tabular}{|c|c|c|c|c|c|c|}
\hline Author/year ${ }^{\mathrm{a}}$ & $\begin{array}{l}\text { Patient } \\
\text { no./c or a }\end{array}$ & Gender & Age (years) & Fracture site & Etiology/co-factor & $\begin{array}{l}\text { Swimming stroke } \\
\text { or/and Work load }\end{array}$ \\
\hline \multirow[t]{2}{*}{ Low, 2016} & $2 / \mathrm{c}$ & $M$ & 15 & $1^{\text {st }}$ rib & $\mathrm{n} / \mathrm{r}$ & Backstroke \\
\hline & & $\mathrm{F}$ & 17 & $\begin{array}{l}1^{\text {st }} \text { rib \& } 2^{\text {nd }} \\
\text { rib (ipsilateral) }\end{array}$ & & Freestyle \\
\hline Heincelman, 2014 & $1 / \mathrm{c}$ & M & 19 & $3^{\text {rd }}$ rib & $\mathrm{n} / \mathrm{r}$ & $\begin{array}{l}\text { Freestyle/backstroke/ } \\
\text { breaststroke/butterfly }\end{array}$ \\
\hline Chaudhury, 2012 & $1 / \mathrm{c}$ & $\mathrm{F}$ & 15 & $1^{\text {st }}$ rib (bilateral) & Regularly play golf & Breaststroke/butterfly \\
\hline Haddad, 1997 & $1 / \mathrm{a}$ & $\mathrm{F}$ & 15 & Femoral neck & $\begin{array}{l}\text { Hip pain while } \\
\text { jogging } 6 \text { weeks } \\
\text { ago (undiagnosed) } \\
\text { Primary amenorrhea }\end{array}$ & Swimming \\
\hline Taimela, 1995 & $1 / \mathrm{c}$ & $\mathrm{F}$ & 21 & $\begin{array}{l}5^{\text {th }} \text { rib \& } 9^{\text {th }} \\
\text { rib (unilateral) }\end{array}$ & $\mathrm{n} / \mathrm{r}$ & $\begin{array}{l}\text { Freestyle } \\
20-25 \mathrm{~h} \text { per week }\end{array}$ \\
\hline Sterling, 1991 & $1 \mathrm{c}$ & M & 14 & Humerus & $\begin{array}{l}\text { Baseball athlete/ } \\
\text { weight lifting } \\
\text { regimen }\end{array}$ & 3-4h per week \\
\hline Woo, 1988 & 1 & $\mathrm{~F}$ & 53 & Fabella & $\begin{array}{l}\text { Osteoarthritic } \\
\text { fabellofemoral joint }\end{array}$ & Breaststroke $>30$ years \\
\hline Kim, 1987 & $1 / \mathrm{c}$ & M & 39 & Pubic ramus & Also diving athlete & Swimming \\
\hline Van Caspel, 1983 & $1 / \mathrm{c}$ & $\mathrm{F}$ & 14 & $\begin{array}{l}\text { Base of the } 1^{\text {st }} \\
\text { metatarsal }\end{array}$ & Use of extra large fins & $\begin{array}{l}\text { Freestyle/backstroke } \\
4-5 \text { workouts/week of } \\
1.5 \text { h each }\end{array}$ \\
\hline Samuel, 1955 & $1 / \mathrm{c}$ & M & 14 & $\begin{array}{l}\text { Posterior aspect } \\
\text { of the tibia }\end{array}$ & $\begin{array}{l}\text { Training for school } \\
\text { sports }\end{array}$ & Up to 900 meters daily \\
\hline
\end{tabular}

a Citations have been listed by the first author's last name to conserve space. Abbreviations: $\mathrm{c}=$ competitive swimmer; $\mathrm{a}=$ amateur swimmer; $\mathrm{M}=$ male; $\mathrm{F}=$ female; $\mathrm{n} / \mathrm{r}=$ not reported. 


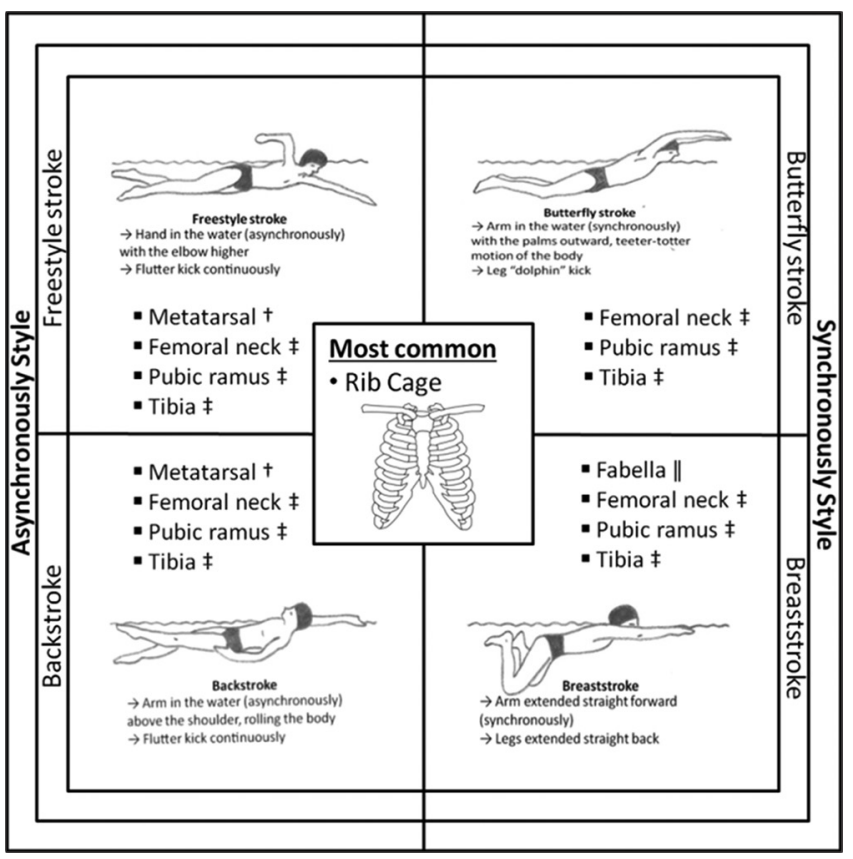

Figure 3. Anatomical locations of stress fractures according the swimming style. Symbols definition: $\uparrow$, use of extra equipment; $\$$, multi-sport participation, $\|$, health problem

\section{Diagnosis - Treatment}

\section{Ribs}

The ribs are the most common site of stress reactions and stress fractures in athletic swimmers (Chaudhury, Hobart, \& Rodeo, 2012; Heincelman et al., 2014; Low, Kern, \& Atanda, 2016; Taimela, Kujala, \& Orava, 1995). The first three pairs of ribs are most commonly affected and the combination of co-contraction forces of the thoracic wall, repeated overhead activity and twisting with bending of the trunk seems to be the etiology of this type of injury (Heincelman et al., 2014; Low, Kern, \& Atanda, 2016). Symptoms include shoulder/ neck pain, pain aggravated by deep breathing; tenderness over peri-scapular musculature and the posterior aspect of the mid-clavicle; paresthesia radiating into the arm, and discomfort during active movements of the shoulder joint (Table 2) (Chaudhury, Hobart, \& Rodeo, 2012; Heincelman et al., 2014; Low, Kern, \& Atanda, 2016; Taimela, Kujala, \& Orava, 1995). Plain radiographs may assist in detecting stress fractures, but have poor sensitivity in the early stages of the evolution of stress fractures. Computed tomography (CT) scan is the best diagnostic tool to detect these fractures, as well as to rule out possible pulmonary embolus (Table 2) (Taimela, Kujala, \& Orava, 1995). The current literature suggests that conservative treatment with analgesia, vitamin D and calcium supplements, as well as a period of time (at least 4 weeks) with activity modification combined with physical therapy is indicated (Table 2) (Wild et al., 2011).

\section{Pubic ramus}

A pubic ramus stress fracture is an extremely rare injury in swimmers, with only one case reported in the literature (Kim, Park, \&Gartland, 1987). This swimming athlete was also a participant in diving competitions. The athlete presents with groin pain, tenderness over the lumbo-sacral joint and depressed Achilles reflex. A history of diving participation reported and may have a role as a co-factor of injury (Table 2). Plain radiographs are initially obtained. If radiographs are negative and the clinical suspicion is high, magnetic resonance imaging (MRI) and bone scan are useful diagnostic modalities to confirm diagnosis of a stress fracture (Kim, Park, \&Gartland, 1987; Van Caspel \& Holden, 1991). Pubic ramus stress fractures are typically treated with an initial period of rest, anti-inflammatory and analgesic medications, as well as physical therapy for at least eight weeks (Bertolini et al., 2011).

\section{Femoral neck}

Femoral stress fractures typically present in long-distance runners (Goolsby, Barrack, \& Nattiv, 2012). In the literature, only one study presents a femoral neck stress fracture in a swimmer. This athlete was also a keen runner and had noted a previous hip pain whilst jogging. Undiagnosed hip pain while jogging in combination with special diet programs or hormonal problems (history of vegan diet, body weight loss, amenorrhea) should arouse suspicions (Table 2) (Haddad et al., 1997). Typical symptoms include hip pain with inability to bear any weight on the affected leg. A plain radiograph is sufficient to make the diagnosis of stress fracture and initiate emergency surgical treatmen (Haddad et al., 1997; Goolsby, Barrack, \& Nattiv, 2012). A well organized post-surgical rehabilitation program for a minimum of 12 weeks is useful in facilitating a quick and safe return to a full routine of daily and sports activities (Goolsby, Barrack, \& Nattiv, 2012).

\section{Fabella}

Stress fractures of the fabella are very rare, with only one case reported in the literature (Woo, 1988). This type of injury is usually reported after direct trauma, repetitive micro-trauma and altered biomechanics in patients with total knee arthroplasty (Tang, Mulcahy, \& Chew, 2010). The primary symptoms include posterolateral localized knee pain and reproduced pain with active or passive extension of the knee (Table 2). Initial radiographs can reveal a radiolucent line which can be regarded as a complete fracture (Woo, 1988). However, if there is no obvious radiographic abnormality, the use of computed tomography can provide a diagnosis (Tang, Mulcahy, \& Chew, 2010). Generally, conservative treatment options are oreferred, such as anti-inflammatory drugs, cryotherapy, transcutaneous electrical nerve stimulation (TENS), strapping and preventing knee from hyperextension (Woo, 1988).

\section{Tibia}

The bone of tibia is one of the commonest bones suffering a stress fracture in runners, not only professional, but also recreational joggers (Sanderlin \& Raspa, 2003; Asano, Duarte Jr, \& Silva, 2014). Only one study, from the distant past, exists describing a stress fracture in the tibia bone in a school boy with a training history of swimming up to 1,000 yards per 
Table 2. Stress fractures, signs and symptoms, examination and treatment options

\begin{tabular}{|c|c|c|c|}
\hline Site & Signs and symptoms & Diagnostic evaluation & Treatment \\
\hline Rib & $\begin{array}{l}\text { Shoulder pain, pleuritic chest } \\
\text { pain, neck pain and/or around } \\
\text { the scapula pain; soreness in } \\
\text { the clavicular region; pain } \\
\text { aggravated by deep breathing; } \\
\text { tenderness over periscapular } \\
\text { musculature and the posterior } \\
\text { aspect of the mid-clavicle; } \\
\text { paresthesia radiating into } \\
\text { the arm; abnormal posture; } \\
\text { scapular winging and } \\
\text { dyskinesia; discomfort with } \\
\text { active shoulder flexion }\end{array}$ & $\begin{array}{l}\text { May be seen on plain } \\
\text { radiograph; May require } \\
\text { bone scan, CT or MRI (to } \\
\text { rule out pulmonary } \\
\text { embolus and detect occult } \\
\text { fractures) }\end{array}$ & $\begin{array}{l}\text { Rest or/and activities } \\
\text { modification; restriction } \\
\text { from overhead activities } \\
\text { and swimming; medication } \\
\text { regimen (anti-inflammatories } \\
\text { drugs, vitamin D, calcium, } \\
\text { calcitonin) }\end{array}$ \\
\hline Humerus & $\begin{array}{l}\text { Pain in the mid-humerual } \\
\text { area; swelling; ecchymosis, } \\
\text { tenderness with active and } \\
\text { passive motion of the arm }\end{array}$ & $\begin{array}{l}\text { Plain radiograph; Bone } \\
\text { scan to rule out benign or } \\
\text { malignant lesions }\end{array}$ & $\begin{array}{l}\text { Rest from stress activities; } \\
\text { application of humeral fracture } \\
\text { brace; Progressive active } \\
\text { ROM; stretching; strengthening } \\
\text { exercises; patient education }\end{array}$ \\
\hline Pubic ramus & $\begin{array}{l}\text { Groin pain; tenderness } \\
\text { over the lumbo-sacral } \\
\text { joint; depressed Achilles } \\
\text { reflex (ipsilateral) }\end{array}$ & Requires bone scan & Restrict physical activities \\
\hline Femoral neck & $\begin{array}{l}\text { Hip and thigh pain; crank } \\
\text { feeling in the groin; no bear } \\
\text { weight on the affected leg }\end{array}$ & $\begin{array}{l}\text { Plain radiograph; May } \\
\text { require bone scan }\end{array}$ & $\begin{array}{l}\text { Surgical urgent reduction and } \\
\text { internal fixation with vascularized } \\
\text { bone graft }\end{array}$ \\
\hline Tibia & $\begin{array}{l}\text { Pain in the upper aspect of the } \\
\text { calf; enlargement in the upper } \\
\text { part of the calf }\end{array}$ & $\begin{array}{l}\text { May be seen on } \\
\text { plain radiograph as } \\
\text { periostitis (immediately) } \\
\text { and as a visible fracture } \\
\text { line (one week later) }\end{array}$ & Protection with plastic cast \\
\hline Fabella & $\begin{array}{l}\text { Knee pain (posterolateral); } \\
\text { painful knee extension (active } \\
\text { and passive) }\end{array}$ & Plain radiograph & $\begin{array}{l}\text { Anti-inflammatory/analgesic } \\
\text { cream; cryotherapy; TENS; } \\
\text { strapping; avoid knee } \\
\text { hyperextension }\end{array}$ \\
\hline First metatarsal & $\begin{array}{l}\text { Foot and ankle pain; swollen } \\
\text { over metatarsus; tenderness } \\
\text { over } 1^{\text {st }} \text { metatarsal and } \\
\text { talo-crural joint }\end{array}$ & $\begin{array}{l}\text { May be seen on plain } \\
\text { radiograph as a visible } \\
\text { small fissure }\end{array}$ & $\begin{array}{l}\text { Foot immobilization with } \\
\text { bandage and tape; crutches } \\
\text { for } 3 \text { weeks; abstain athletic } \\
\text { activities; gradually increase } \\
\text { loading of the foot }\end{array}$ \\
\hline
\end{tabular}

$\mathrm{CT}=$ computed tomography; $\mathrm{MRI}=$ magnetic resonance imaging; $\mathrm{ROM}=$ range of motion; TENS=transcutaneous electrical nerve stimulation

day (Samuel, 1955). However, a possible aggravating factor included training for school sports. These stress fractures present with local pain and tenderness over the tibia which increases with exercise (Table 2). The diagnosis is primarily collected from a medical history and clinical examination, but imaging with plain radiograph is often negative in the early stages, as positive findings may take one week to appear. Usually, conservative treatment is indicated with the application of a leg cast until the patient is pain-free and there is radiographic evidence of healing (Sanderlin \& Raspa, 2003).

\section{Metatarsal}

The most common sites for stress fractures in the foot are the metatarsal bones, and present most commonly among military recruits and ballet dancers (Sanderlin \& Raspa, 2003). There is only one case report found in the literature of a stress fracture in the first metatarsal of a young female competitive swimmer (Van Caspel \& Heere, 1983). However, the use of extra large fins during training has been suggested as a possible etiologic factor of metatarsal stress fracture. Injured athletes typically present with pain, swollen, tenderness and difficulties with walking (Table 2) (Hatch, Alsobrook, \& Clugston, 2007). Plain radiographs can demonstrate the presence of a small fissure, but generally may not reveal a stress fracture in the first 2-3 days. Because of these difficulties, a confirmatory diagnosis has sometimes been made using an MRI or bone scan. Conservative treatment is the accepted management modality, with foot immobilization, the use of crutches and gradually 
loading of the foot (Van Caspel \& Heere, 1983; Hatch, Alsobrook, \& Clugston, 2007).

\section{Humerus}

Stress fracture of the humerus is a quite uncommon injury with this type of injury occurs particularly among overhead athletes, such as tennis player and baseball pitcher (Sterling, Calvo, \& Holden, 1991). This review demonstrate one case report of a humeral fracture in a young athlete which are competing in multiple sports, such as baseball, weight lifting and swimming, as a result of an undiagnosed stress fracture. Patients commonly present with indolent pain with a duration of symptoms for several weeks. Initial radiographs are often negative and it can take several weeks for a periosteal reaction to become radiographically visible. A combination of plain radiograph, MRI and CT are characteristic of this pattern of injury. Early diagnosis of this injury and early activity modification, even without immobilization, can lead to resolution of symptoms (Sterling, Calvo, \& Holden, 1991).

\section{DISCUSSION}

Clinical impression suggests that stress fractures are common injuries most often associated with participation in sports involving running, jumping or repetitive stress. Although almost any sport activity can cause stress fractures, competitive swimming seems to be relatively safe in this respect. Incidence rate among swimmers is typically difficult to estimate due to various factors, such as the unusual occurrence of this type of injury, and the reported single case studies in the literature. From the literature, one study has provided very low incidence rate (ranging from 0.58 to 1.66) in collegiate student athletes who participate in swimming and diving (Rizzone et al., 2017). However, it is difficult to compare the incidence of stress fractures in different sports because of a lack of sound epidemiologic data.

A literature review covering the last 60 years regarding stress fractures in swimmers revealed only a few cases of this injury affecting either the bones of the trunk (rib cage), or even other bones of the human skeleton, such as tibia (Samuel, 1955), femoral neck (Haddad et al., 1997), pubic ramus (Kim, Park, \& Gartland, 1987), metatarsal (Van Caspel \& Heere, 1983), fabella (Woo, 1988) and humerus (Sterling, Calvo, \& Holden, 1991). The development of stress fractures in other bones beyond ribs may be due to the presence of a co-factor, such as special diet programs or hormonal problems, parallel participation in a variety of sports and the use of extra equipment. It is well-documented that the pathogenesis of stress fractures is based on the unsuccessful adaptation of bone to a change in its new mechanical environment caused by repetitive loading (Sterling, Calvo, \& Holden, 1991). From a biomechanical point of view, the rib cage is affected by the greatest loads during coordinated movements of breathing, arm movements and trunk rotation in swimming (Taimela, Kujala, \& Orava, 1995; DiFiori et al., 2014). As result, stress fractures in competitive swimmers occur in the rib cage and especially in the first three sets of ribs. Stress fractures involving ribs can be a clinically important entity in swimmers with persistent or new shoulder, neck or/.and pleuritic chest pain after training for swimming competitions. Also, the fact that all swimmers with rib stress fractures had pain aggravated by deep breathing and discomfort with active shoulder range of motion suggest that such abnormality is of clinical importance.

\section{CONCLUSION}

The analysis of the literature revealed that although any sport activity can potential cause a stress fracture, competitive swimming seems to be relatively safe in this respect. Because of the great number of stroke repetitions and force generated through the upper extremities, the ribs appear as the most common site to sustain a stress fracture in competitive swimmers that clinicians should consider. An understanding of swimming biomechanics aids in prompt recognition of injury, initiation of treatment, shorten the time required for healing, and decrease the risk of complication.

\section{REFERENCES}

Asano, L. Y. J., Duarte Jr, A., \& Silva, A. P. S. (2014). Stress fractures in the foot and ankle of athletes. Revista da Associação Médica Brasileira, 60, 512-517.

Bertolini, F. M., Vieira, R. B., de Oliveira, L. H. A., Lasmar, R. P., \& de Oliveira Jr, O. (2011). Pubis stress fracture in a 15-year-old soccer player. Revista Brasileira de Ortopedia, 46, 464-467.

Breithaupt, M. D. (1855). The pathology of the human foot. Medizin Zeitung, 24, 169-175.

Chaudhury, S., Hobart, S. J., \& Rodeo, S. A. (2012). Bilateral first rib stress fractures in a female swimmer: a case report. Journal of Shoulder and Elbow Surgery, 21, 6-10. doi:10.1016/j.jse.2011.08.048

DiFiori, J. P., Benjamin, H. J., Brenner, J., Gregory, A., Jayanthi, N., Landry, G. L., \& Luke, A. (2014). Overuse injuries and burnout in youth sports: a position statement from the American Medical Society for Sports Medicine. Clinical Journal of Sport Medicine, 24, 3-20. doi:10.1097/JSM.0000000000000060

Goolsby, M. A., Barrack, M. T., \& Nattiv, A. (2012). A displaced femoral neck stress fracture in an amenorrheic adolescent female runner. Sports Health, 4, 352-356. doi:10.1177/1941738111429929

Haddad, F. S., Bann, S., Hill, R. A., \& Jones, D. H. A. (1997). Displaced stress fracture of the femoral neck in an active amenorrhoeic adolescent. British Journal of Sports Medicine, 31, 70-72.

Hatch, R. L., Alsobrook, J. A., \& Clugston, J. R. (2007). Diagnosis and management of metatarsal fractures. American Family Physician, 76, 817-826.

Heincelman, C., Brown, S., England, E., Mehta, K., \& Wissman, R. D. (2014). Stress injury of the rib in a swimmer. Skeletal Radiology, 43, 1297-1299. doi:10.1007/ s00256-014-1863-0

Kim, S. M., Park, C. H., \& Gartland, J. J. (1987). Stress fracture of the pubic ramus in a swimmer. Clinical Nuclear Medicine, 12, 118-119. 
Lazar, J. M., Khanna, N., Chesler, R., \& Salciccioli L. (2013). Swimming and the heart. International Journal of Cardiology, 168(1), 19-26. doi: 10.1016/j.ijcard.2013.03.063.

Lee, N., \& Kim, J. (2015). A review of the effect of swim training and nutrition on bone mineral density in female athletes. Journal of Exercise Nutrition \& Biochemistry, 19, 273-279. doi:10.5717/jenb.2015.15113001

Low, S., Kern, M., \& Atanda, A. (2016). First-rib stress fracture in two adolescent swimmers: a case report. Journal of Sports Sciences, 34, 1266-1270. doi:10.1080/026404 14.2015.1108452

Martens, J., Figueiredo, P., \& Daly, D. (2015). Electromyography in the four competitive swimming strokes: a systematic review. Journal of Electromyography and Kinesiology, 25, 273-291. doi:10.1016/j.jelekin.2014.12.003

Mayer, S. W., Joyner, P. W., Almekinders, L. C., \& Parekh, S. G. (2014). Stress fractures of the foot and ankle in athletes. Sports Health, 6(6), 481-491. doi: $10.1177 / 1941738113486588$.

Pirker, H. (1934). Bruch der Oberschenkeldiaphyse durch Muskelzug. Archiv für Klinische Chirurgie, 175, 155-168.

Rizzone, K. H., Ackerman, K. E., Roos, K. G., Dompier, T. P., \& Kerr, Z. Y. (2017). The epidemiology of stress fractures in collegiate student-athletes, 2004-2005 through 2013-2014 academic years. Journal of Athletic Training, 52(10), 966-975. doi: 10.4085/1062-6050-52.8.01

Samuel, E. (1955). Radiological case book. XXXIX. Fatigue (insufficiency) fracture of the tibia. South African Medical Journal, 29, 89-90.
Sanderlin, B. W., \& Raspa, R. F. (2003). Common stress fractures. American Family Physician, 68, 1527-1532.

Secchi, L. L. B., Muratt, M. D., Andrade, N. V. S., \& Greve, J. M. A. (2010). Isokinetic trunk dynamometry in different swimming strokes. Acta Ortopédica Brasileira, 18, 295-297.

Sterling, J. C., Calvo, R. D., \& Holden, S. C. (1991). An unusual stress fracture in a multiple sport athlete. Medicne \& Science in Sports \& Exercise, 23, 298-303.

Taimela, S., Kujala, U. M., \& Orava, S. (1995). Two consecutive rib stress fractures in a female competitive swimmer. Clinical Journal of Sport Medicine, 5, 254-256.

Tang, J. Y., Mulcahy, H., \& Chew, F. (2010). High-energy fracture of the fabella. Radiology Case Reports, 5, 454. doi: 10.2484/rcr.v514.454

Tins, B. J., Garton, M., Cassar-Pullicino, V. N., Tyrrell, P. N., Lalam, R., \& Singh, J. (2015). Stress fracture of the pelvis and lower limbs including atypical femoral fractures-a review. Insights Imaging, 6, 97-110. doi:10.1007/ s13244-014-0371-Z

Van Caspel, J., \& Heere, L. P. (1983). Stress fracture of the os metatarsale I in a swimmer. Biomechanincs and Medicine in Swimming, 14, 28-31.

Wild, A. T., Begly, J. P., Garzon-Muvdi, J., Desai, P., \& McFarland, E. G. (2011). First-rib stress fracture in a high-school lacrosse player: a case report and short clinical review. Sports Health, 3, 547-549. doi: $10.1177 / 1941738111416189$

Woo, C. C. (1988). Fracture of the fabella. Journal of Manipulative and Physiological Therapeutics, 11, 422-425. 